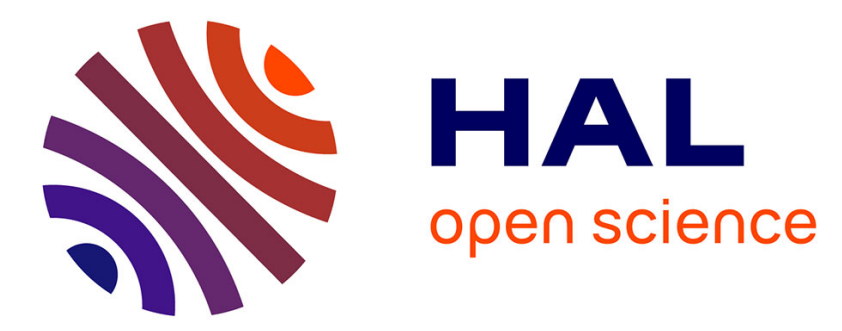

\title{
Distribution of naturally occurring radionuclides (U, Th) in Timahdit black shale (Morocco)
}

\author{
C. Galindo, L. Mougin, S. Fakhi, A. Nourreddine, A. Lamghari, H. Hannache
}

\section{To cite this version:}

C. Galindo, L. Mougin, S. Fakhi, A. Nourreddine, A. Lamghari, et al.. Distribution of naturally occurring radionuclides (U, Th) in Timahdit black shale (Morocco). Journal of Environmental Radioactivity, 2007, 92, pp.41-54. 10.1016/j.jenvrad.2006.09.005 . in2p3-00133780

\section{HAL Id: in2p3-00133780 \\ https://hal.in2p3.fr/in2p3-00133780}

Submitted on 27 Feb 2007

HAL is a multi-disciplinary open access archive for the deposit and dissemination of scientific research documents, whether they are published or not. The documents may come from teaching and research institutions in France or abroad, or from public or private research centers.
L'archive ouverte pluridisciplinaire HAL, est destinée au dépôt et à la diffusion de documents scientifiques de niveau recherche, publiés ou non, émanant des établissements d'enseignement et de recherche français ou étrangers, des laboratoires publics ou privés. 


\title{
DISTRIBUTION OF NATURALLY OCCURRING RADIONUCLIDES (U, Th) \\ IN TIMAHDIT'S BLACK SHALE (MOROCCO)
}

\author{
C. Galindo ${ }^{1^{*}}$, L. Mougin ${ }^{1}$, S. Fakhi ${ }^{2}$, A. Nourreddine ${ }^{1}$, A. Lamghari ${ }^{1}$, H Hannache ${ }^{3}$ \\ ${ }^{1}$ Institut Pluridisciplinaire Hubert Curien \\ 23, rue du Loess BP28 67037 Strasbourg Cedex 2 \\ ${ }^{2}$ Laboratoire de Radiochimie (LRC) \\ Faculté des Sciences Ben M'sik, Casablanca, Maroc \\ ${ }^{3}$ Laboratoire de Matériaux Thérmo-Structuraux Faculté des Sciences Ben M'sik, Casablanca, \\ Maroc \\ * : corresponding author (Catherine.galindo@ires.in2p3.fr, \\ Phone: (+33)(0)3 88106676 - Fax: (+33)(0)3 881064 31)
}

\begin{abstract}
Attention has been recently focused on the use of Moroccan's black oil shales as the raw materials for production of a new type of adsorbents and their application on the $\mathrm{U}$ and $\mathrm{Th}$ isotope adsorption tests. The purpose of the present work was to provide a better understanding of the fine composition and structure of such materials and to determine their natural intrinsic content in uranium and thorium. A black shale collected from Timahdit (Morocco) was analyzed by powder X-ray diffraction and SEM techniques. It was found that calcite, dolomite, quartz, clays constitute the main bulk composition of inorganic matrix. Pyrite crystals are also present. Selective leaching procedure, followed by radiochemical purification and alpha-counting, was performed to assess the distribution of naturally occurring radionuclides. Leaching results indicate that ${ }^{238} \mathrm{U},{ }^{235} \mathrm{U},{ }^{234} \mathrm{U},{ }^{232} \mathrm{Th},{ }^{230} \mathrm{Th},{ }^{228} \mathrm{Th}$ have multiples modes of occurrence in the Moroccan's black shale. Uranium was interpreted to have been concentrated under anaerobic environment. An integrated isotopic approach points out the preferential mobilization of uranium carried by humic acids to carbonates and apatite phases. Thorium is partitioned between silicate minerals and pyrite.
\end{abstract}

Keywords: uranium - thorium - black shale - mineralogy - radiochemical separations sequential extractions 


\section{Introduction}

To satisfy the increasing number of directives referring to the control of natural and artificial radioactivity, numerous operational new methods of analysis, measure (Azouazi et al, 2001) and treatment (Morvan et al, 2001) of radionuclides and conditioning processes of radioactive waste have been developed. Within this context, previous work was aimed at producing new adsorbents and testing them for their potential in the trapping of radionuclides like $U$ and Th isotopes (Bekri et al, 1991). These adsorbents were produced from oil shale, which is abundant in Morocco. The choice of this material was dictated by its composition, as it contains a large amount of organic matter chemically linked to a mineral matrix. (El. Khouya et al, 2004); it has also proved to possess good capacities to remove some organic substances, heavy metals and bacterium (Oumam et al, 2002).

However, naturally radioactive elements tend to have a far greater concentration in black shales than in other sedimentary lithologies (Adams et al, 1958). Thermal processing or chemical activation used to produce adsorbents may induce a release of these radionuclides into the ecosystem. The extent to which these releases occur depends largely on the manner in which the element is bound to the sediment and on how the kinds of bounds react to various physicochemical conditions. It is then suitable to define the modes of occurrence of the naturally radioactive elements in the raw material. One of the best methods to perform indirect research on radionuclide speciation in soils and sediments is the sequential extraction (Blanco et al, 2005, Schultz et al, 1998). Two protocols of extractions have attained the rank of standards: Tessier's method (Tessier et al, 1979) and the BCR method (Quevauviller et al, 1993). In the present work, the mineralogical composition of a black shale specimen collected in the region of Timahdit, in the mid-Atlas mountain, was determined by X-ray diffraction (XRD), scanning electron microscopy (SEM). A sequential leaching procedure based on the Tessier's method was used to define the speciation of isotopes of uranium and thorium in the black shale. Some important stable elements were quantified simultaneously, to get more information about the geochemical association of these radioactive nuclides. 


\section{Experimental section}

\subsection{Sampling location}

The black shale specimen used in this investigation was collected in the region of Timahdit located in the mid-Atlas mountain at $35 \mathrm{~km}$ in the south of Azrou. This deposit is a vein of schist 100-150 m thick. The discovery of fossils in the Formation has placed the black shale sequence in the Maastrichtian age (Rahhali, 1970). The lithography of the studied area has been extensively described by Benlioulhaj (1991). In brief, three distinct layers have been differentiated. The sample used in the present work was extracted from the middle sequence, which is the richest in organic matter, with an organic content ranging from $5 \%$ from $20 \%$.

\subsection{Mineralogical characterization of the natural black shale}

Mineralogical studies of the raw material were performed by X-ray diffraction using a Philips Analytical diffractometer (anticathode $\mathrm{Cu}, 40 \mathrm{kV}-20 \mathrm{~mA}$ ). The morphology of the minerals and their semi-quantitative chemical analysis were obtained with a JEOL-840 scanning electron microscope, equipped with an energy dispersive spectrometry system.

\subsection{Elemental and isotopic balances in the leached black shale}

To quantify the elemental and isotopic balances in the leached black shale, the following experimental sequence was carried out:

\subsubsection{Sequential extractions}

Sequential extractions have been applied using extractants with progressively increasing extraction capacity. Although initially thought to distinguish some well-defined chemical forms of trace metals, they rather address operationally defined fractions, the selectivity of some extractants being somewhat weak or not sufficiently understood. The sequential extractions, described in Table 1, were performed under oxic conditions in constantly agitated centrifuge tubes, with a sample size of $3 \mathrm{~g}$. After each extraction stage, supernatant was separated from the residue by centrifugation at $3000 \times \mathrm{g}$ for $15 \mathrm{~min}$ and then filtrated through a $0.45 \mu \mathrm{m}$ membrane filter into polypropylene bottles for analysis. Residue was rinsed twice with deionised 
water, hand shaken and separated by centrifugation and filtration. The inclusion of the filtration step proved necessary for adequate phase separation and reproducibility (Schultz, 1998).

\subsubsection{Stable elements determination}

The chemical composition ( $\mathrm{Al}, \mathrm{Si}, \mathrm{P}, \mathrm{Fe}, \mathrm{K}, \mathrm{Ca}, \mathrm{Mn}$ ) of the different extracts was determined using ICP-AES methods. The unaltered oil shale sample and the residue obtained at the end of the extraction procedure were previously dissolved using $\mathrm{HNO}_{3} / \mathrm{HCl} / \mathrm{HF}$. The calcite content was determined using a Bernard calcimeter.

\subsection{2. $\quad \underline{U}$ and Th isotopes determination}

\section{a) Radiochemical separation:}

The solid sample $(0.5 \mathrm{~g}$ of the raw oil shale and $0.2 \mathrm{~g}$ of the residues obtained at the last stage of the sequential extractions) were ground, ashed at $850^{\circ} \mathrm{C}$ during $2 \mathrm{~h}$ and completely dissolved by peroxide fusion. The leaching solutions generated during the extraction procedure were acidified at $\mathrm{pH}<1$ with concentrated hydrochloric acid and stored at $4^{\circ} \mathrm{C}$ before any chemical treatment.

The subsequent radiochemical procedure included enrichment of the radionuclides by coprecipitation with iron hydroxide. Uranium and thorium were subsequently isolated by conventional anionic exchange and extraction chromatography, followed by an electroplating step. The whole procedure, depicted in Figure 1, has been extensively described by Galindo et al (2005). ${ }^{232} U$ in equilibrium with its daughters has been used as chemical yield. In case of thorium analysis, the procedure was performed twice: once with the yield determinant and once, without it.

\section{b) Alpha spectrometry analysis}

Alpha spectra were recorded using $450 \mathrm{~mm}^{2}$ PIPS detectors mounted in vacuum chambers and coupled to the associated electronics AlphaAnalyst (Canberra Electronique, Savigny-le-Temple, France). The optimum source - detector distance was established in $6 \mathrm{~mm}$. At this distance, the detection efficiency was about $25 \%$ and the resolution acceptable. The acquisition times ranged from 1 to 14 days, depending on the activity level of the source. Background measurements were repeated all 10 counting for uranium determination and all 2 counting for thorium measurements. Spectra were analyzed with the VisuAlpha software (AMS). 


\section{Results}

\section{Mineralogical characterization}

The black shale is neutral with a pH value of 6.9 at a sample:water of 1:4. According to SEM analysis, the structure is very compact, with a very low porosity. As presented in Figure 2a, euhedral mineral crystals are dispersed in a matrix resulting from an intimate association between clays and organic matter. Earlier studies indicated that organic matter, mainly kerogen and, in a slighter extent, humic acids, contribute to around 17 weight \% of the sample (Ichcho, 2003). The main mineral phases, as identified by XRD and SEM (Fig. 2) are quartz, clays, calcite and dolomite. Accessory minerals consist of pyrite, apatite, anhydrite, feldspars (orthoclase, microcline, anorthite), sphalerite. The absence of peak relative to chloride and fluoride on the apatite crystal indicates that hydroxyl-apatite is the dominant apatite form. According to the studies of Benlioulhaj (1991), except in well-defined decimetric marls, in which the apatite content may reach $50 \%$, apatite represents at most 4 weight $\%$ of the sediment, in the whole vein of schist, and consequently in the specimen used. Clay assemblage consists of kaolinite, smectite, interstratified illite - smectite and illite. The latter contains minor titanium and some iron. Theses clays minerals represent the main components of the terrigenous detritus. No iron and manganese oxyhydroxides could be detected by both above-mentioned techniques. Pyrite is also the sole iron-bearing diagenetic mineral. It occurs as typical framboidal, as illustrated in Figure 2, and euhedral forms. It reflects a marine influence on the depositional environment with a continental iron influx.

The elementary analysis of the bulk black shale is given in Table 2. Among major elements, the high concentration of total carbon is highlighted. This $C$ is assigned partly to organic carbon and to carbonates. According to thermo-gravimetric analysis, calcite and dolomite represent respectively 14.2 and 4.4 weight \% of the sample (Ichcho, 2003). A comparable result has been obtained, in the present study, for calcite using the Bernard calcimeter $(13.6 \% \pm 0.6 \%)$.

In order to gain information on the role of sediment components in binding/retaining trace elements, especially actinides, sequential extraction procedure was carried out. The distribution patterns of some characteristic metals in the black shale fractions after application of the 
selected speciation methods are presented in Fig. 3. The portion of leached element in the different fraction was calculated on the basis of the total concentration of this element in the bulk sample. The sum of the total extracted element content and the inaccessible residual element amounts are equal to the initial content within the experimental error range. This feature reflects that no loss of elements occurred during the experiment. On the other hand, two replicate splits were extracted and analyzed to assess the reproducibility of the procedure. The results for all the elements were reproducible within $3 \%$.

\section{Slightly extracted elements :}

Silicon, potassium: Silicon and potassium are the elements used to check the selectivity of the leaching procedure. Indeed, silicate materials should not experienced severe attack and should be preserved during the experiment. Experiments show that $\mathrm{Si}$ and $\mathrm{K}$ remain actually in the residue: less that respectively 0.5 and $4 \%$ of the total $\mathrm{Si}$ and $\mathrm{K}$ have been detected in fractions F1 to F5.

Aluminum: As expected, the strongly hydrolyzing element aluminum was measured almost exclusively in the F6 fraction. It is predominantly residual, being one of the major constituents of clay minerals, feldspars. As only traces of silicon and potassium, typical indicators for hydrated aluminosilicates, are observed in fraction F5, one can expect that the amount detectable in this organic fraction actually corresponds to aluminium bound to organic matter. Nevertheless, it contributes to at most $4 \%$ of the total aluminium.

Iron: $23 \%$ of the total iron is accumulated as part of the organic sulphide fraction, indicating a pyrite association. Most of iron remains however in the residual fraction, which is a proof of a silicate association. The lack of iron extracted by hydroxylammonium chloride (F4) implies that no $\mathrm{Fe}$ is partitioned in amorphous and poorly crystalline hydroxides, as expected from SEM and XRD measurements. 


\section{Easily exchangeable elements :}

Manganese : Mn speciation is distinguished from the majority of the cations. $22 \%$ remains in the residue and $5 \%$ are exchangeable (F2), implying partitioning into clays and/ or in minor XRDundetectable $\mathrm{Mn}(\mathrm{II})$ well-crystalline oxides localized inside the phyllosilicate structure, filling interlaminar eye-like voids originated by an adaptation process between two different sized adjacent sheets (Ryan et al, 2002). The high proportion of manganese extracted during step F3 (48\%) implies that $\mathrm{Mn}$ is primarily present in carbonates. However, leaching does not allow determining whether calcite manganese is chemisorbed or structural. Part of this element dissolved in the reducible fraction (F4) can result from residual Mn-carbonates or from oxyhydroxides. Nevertheless, its concentration is too low for the mineral phases associated with this element to be considered as efficient trace metal collectors.

Phosphorus: Phosphorus is collected concomitantly with calcium in the more acidic fractions $(\mathrm{F} 4, \mathrm{~F} 5)$ and in the residue (F6). It is suggested that a $\mathrm{P}$ - and Ca-bearing mineral, i.e. apatite, would be dissolved during the step F4 due to the acidic conditions $(\mathrm{pH}=2)$. According to the sequential extraction method, organic phosphorus and the less mobile forms, i.e. phosphorus localized in interlayer sites in clays, account for $52 \%$ and $22 \%$ of the total concentration, respectively. These contents may be somewhat overestimated due to an incomplete dissolution of phosphate minerals in $\mathrm{F} 4$ fraction.

Calcium: Calcium occurs in easily mobile forms in the black shale, since approximately $77 \%$ of its total concentration was observed in the first 4 extraction steps. The main sources, within a $54 \%$ content, are calcite and dolomite, which are dissolved by leaching with acetate in acidic media. Anhydrite is the sole water soluble calcium-bearing mineral detected by XRD and SEM; it must be taken into account to explain the calcium release in fraction $\mathrm{F} 1$. The $\mathrm{Ca}^{2+}$ ions collected in F2 may be identified as easily exchangeable ions located in interlayer sites in clays or as resulting from prematurely dissolved carbonates. It is worth noting that only few $\mathrm{Ca}$ bearing silicate minerals (anorthite) are detected in the black shale using SEM and XRD 
techniques. Leaching experiments confirm this observation, since only $7 \%$ of the total calcium concentration remains in the residual fraction.

\section{Radiochemical analysis of the M layer of Timahdit's black shale}

The activities of the natural radionuclides ${ }^{238} \mathrm{U},{ }^{235} \mathrm{U},{ }^{234} \mathrm{U},{ }^{232} \mathrm{Th},{ }^{230} \mathrm{Th}$ and ${ }^{228} \mathrm{Th}$ in the bulk black shale sample are given in Table 3. The ${ }^{234} \mathrm{U} /{ }^{238} \mathrm{U}$ and ${ }^{228} \mathrm{Th} /{ }^{232} \mathrm{Th}$ activity ratio (AR) are near unity. In contrast, there is a large excess of ${ }^{230} \mathrm{Th}$ as compared to ${ }^{232} \mathrm{Th}$.

Distribution of uranium : The abrupt changes observed in distribution in the 6 fractions of the sequential extraction procedure indicate the presence of discrete phases with which uranium may be associated. The uranium concentration in the acetate fraction (F3) ranges about 4.3 ppm, indicating incorporation in calcium carbonates. A small but significant quantity of uranium, $4 \%$ of the total, could be extracted with a neutral electrolyte solution (F2), thus suggesting either surface reaction fixation, through outer-sphere complexes or an association with prematurely dissolved carbonates. The latter interpretation is more likely since the ${ }^{234} \mathrm{U} /{ }^{238} \mathrm{U} A R$ are equal in $F 2$ and $F 3$ fractions, i.e. ${ }^{234} \mathrm{U} /{ }^{238} \mathrm{U}=1.9 \pm 0.2$. Apatite represents a noteworthy pool for uranium, as $8 \%$ of the total uranium is removed during step F4 of the extraction procedure. It is characterized by a large excess of ${ }^{234} \mathrm{U}$ in comparison to ${ }^{238} \mathrm{U}$, with $\mathrm{a}^{234} \mathrm{U} /{ }^{238} \mathrm{U}$ AR of $1.4 \pm 0.1$. Various line of evidence suggest that, due to the similarity in their ionic radii, $\mathrm{U}^{4+}$ directly substitutes $\mathrm{Ca}^{2+}$ ions in the apatite structure after being initially adsorbed on to its surface (Ivanovich, 1992). Only 3\% of total uranium remains in the final residue indicating that silicate minerals $\left({ }^{234} \mathrm{U} /{ }^{238} \mathrm{U}=1.01 \pm 0.09\right)$ are not efficient uranium scavengers.

Uranium removed during step F5 contributes to $74 \%$ of the total $U$. The use, for the extraction of oxidizing species, i.e. $\mathrm{H}_{2} \mathrm{O}_{2}$ in $\mathrm{HNO}_{3}$, produces an ambiguous distinction between the partitioning of analytes associated with organic matter and pyrite. Consequently, additional extractions were conducted. Two successive leaching by $6 \mathrm{M} \mathrm{HCl}$ and concentrated $\mathrm{HF}$ induce the destruction of carbonates, apatite, clays minerals, quartz. The chemical method alters the structure of humic acids, so that part of the organic carbon is lost during the demineralization process. In contrast, kerogen and some accessory minerals, such as pyrite, remain unaltered 
after these acid attacks. Only $1.28 \mathrm{ppm}$ of uranium was detected in the residual materials, so that the resistate, especially pyrite, contributes to at most $3 \%$ of the total uranium. Pyrite is also a minor mode of occurrence of uranium. This result is in agreement with the relatively low adsorption capacity of iron disulfide for reduced uranium (Delécaut, 2004).

Therefore, retention of $U$ by organic matter, either by adsorption or as organo-complexes, controls the uranium budget of the sediment. The corresponding ${ }^{234} \mathrm{U} /{ }^{238} \mathrm{U}$ AR is about 0.8 . This experiment also gives an insight into the nature of the organic matter involved in actinide retention. As previously mentioned, organic matter in Timahdit's black shale is composed of some water-soluble complexes (especially amino-acids), humic acids and kerogen. The latter is the most abundant; it corresponds to an advanced stage in the evolution of sedimentary organic matter. Since it is highly resistant to leaching by $\mathrm{HCl} / \mathrm{HF}$, one can deduce that it contributes, with pyrite, to less than $3 \%$ of the total uranium. It is also an inefficient uranium carrier. The contribution of water-soluble complexes has been evaluated by leaching by deionised water (fraction F1) and was likewise considered as negligible. Consequently, most of the actinide is associated with kerogen precursor, i.e. humic acids, which are characterized by many functional groups and hetero-atoms able to complex inorganic ions and which are subject to degradation via prolonged $\mathrm{HCl} / \mathrm{HF}$ leaching, releasing these associated trace elements. Besides, Benlioulhaj (1991) reported that transition metals, such as Al, Fe, are less concentrated in kerogen than in humic acids, so that their behaviour is very similar to that of uranium.

Thorium: A distinction must be done between ${ }^{230} \mathrm{Th}$ and ${ }^{232} \mathrm{Th}$. The former belongs to the ${ }^{238} \mathrm{U}$ decay series, so that its activity depends partly on the concentration in the sediment of its supporting source ${ }^{234} \mathrm{U}$, whereas ${ }^{232} \mathrm{Th}$ corresponds to a detrital input.

Silicate and organic/sulfite fractions are dominating the ${ }^{232}$ Th content of the black shale. $49 \%$ of the actinide remains in the residue at the end of the extraction procedure and $51 \%$ are released by treatment with $\mathrm{H}_{2} \mathrm{O}_{2}$ in nitric acid. Most of the thorium collected in fraction F5 was not found to be $\mathrm{HCl}$ and $\mathrm{HF}$ soluble. Therefore, humic acids represent only a minor sink for thorium. One can postulate that the majority of the actinide detected in F5 resides in accessory minerals resistant to HF attack, such as pyrite or, less probably in kerogen. The involvement of monazite 
must be excluded since no traces of phosphorus remain in the resistate material after $\mathrm{HCl}$ and HF treatment. The absence of ${ }^{232} \mathrm{Th}$ in the fractions attributed to the carbonates and apatite points to an diagenetic origin of these mineral phases.

As for ${ }^{232} \mathrm{Th}$, the organic/sulfite fraction and the resistant matrix control the ${ }^{230} \mathrm{Th}$ budget in the sediment, with $74 \%$ and $18 \%$ of the total activity, respectively. Much lower activity levels were detected in the carbonates (F3: $0.8 \%)$, apatite (F4: $0.8 \%)$ fractions and in the water soluble one (F1: $5 \%)$. The latter can be attributed to the dissolution of some water-soluble organic complexes.

\section{Discussion}

\section{General considerations:}

The ${ }^{234} \mathrm{U} /{ }^{238} \mathrm{U}$ and ${ }^{230} \mathrm{Th} /{ }^{238} \mathrm{U}$ AR are close to unity in the bulk sample, so that ${ }^{238} \mathrm{U},{ }^{234} \mathrm{U}$ and

${ }^{230} \mathrm{Th}$ are considered to be in radioactive equilibrium within $\pm 2 \sigma$ uncertainties. As the ${ }^{228} \mathrm{Th} /{ }^{232} \mathrm{Th}$ AR is nearly unity, ${ }^{228}$ Ra probably remains in the sediment with no significant loss. This may be an indication that uranium-bearing phases are enclosed in kerogenic compounds which have protected them from the weathering processes, or that chemical weathering is minimal. The presence of fresh pyrite provides additional evidence that the sample is well preserved. According to statistical calculations by Yudovich et al (1990), the geochemical background for uranium concentration in black shales is $4-25 \mathrm{ppm}$. The substantially high uranium content $(42.5$ ppm) observed in the M layer of Timahdit's black shale also belongs to anomalous values. Klinkhammer and Palmer (1991) reported that sediments rich in organic matter can contain high concentrations of uranium. Swanson (1956) proposed that adsorption of uranium by organic matter concentrates uranium in black shales. Polar organic molecules contained in humic acids, particularly short-chain aliphatic carboxylate ions, are known to be capable of complexing the more common rock-forming metals. Our experiments showed that they are actually responsible for the complexation of uranium. However, a more recent consideration of the problem of uranium accumulation in sedimentary rocks indicates that the high organic carbon content alone does not govern the uranium concentration (Kochenov et al, 2002). U-bearing shales are systematically characterized by an association of organic matter and calcium phosphates, 
irrespective of the quantitative relationship between these components. Moreover, these minerals systematically show features typical of sediments of anoxic basins. The Timahdit's black shale does not depart from this rule.

Alpha counting indicates that ${ }^{238} \mathrm{U}$ activity is 24 times higher than that of ${ }^{232} \mathrm{Th}$, leading to a Th / U mass ratio much lower than the expected for normal shale (3.6 to 4.7, Taylor and Mc Lennan, 1985). This Th / U mass ratio can be used to distinguish between anoxic, dysaerobic and oxic depositional environments. Thorium is relatively immobile in the sedimentary environment and it owes its source solely from continental landmass. In contrast, uranium measured in the unaltered black shale may consist of two components: a detrital present in terrestrially derived mineral phases and an authigenic derived from sea water (Rosing et al, 2004; Algeo et al, 2004). In fact, unlike thorium, uranium is carried partly in solution as uranyl carbonate complexes. Under reducing conditions, $\mathrm{U}(\mathrm{VI})$ is reduced to $\mathrm{U}^{4+}$, which is not stable in solution and precipitates in the sediment. Enrichment of such authigenic uranium can be calculated by the formula (Wignall et al, 1988):

$\left[U_{a}\right]=[U]-\frac{[T h]}{3}$ where the square brackets represent the concentration expressed in ppm. $U_{a}$ content is extremely high, as it represents $96 \%$ of the total uranium. This uranium is interpreted to have been concentrated under anaerobic environment. The presence of tiny pyrite framboids $(<4 \mu \mathrm{m}$ mean diameter) actually points to anoxic conditions and sulphate reduction processes during deposition and early diagenesis (Wignall et al, 1998; Wilkin et al, 1996). The lack of amorphous iron oxides and the fact that the majority of manganese exists in reduced forms confirm such reducing conditions.

The high organic content and the inferred reducing conditions provided conditions conductive to anoxic breakdown of the humic acids during early diagenesis, leading to a redistribution of associated trace elements with mineral phases already present in the sediment or the involvement of the released inorganic ions in mineral neo-formations. In particular, calcite and dolomite were determined to be diagenetic, judging by their very low thorium-232 concentration (lower than detection limit), all the more that incorporation of uranium in the marine sediment by 
uptake in calcareous plankton, corals and molluscs does not lead to uranium content as high as $4.3 \mathrm{ppm}$, i.e. the actinide concentration measured in the carbonaceous fraction (F3) (Ivanovich et al, 1992).

\section{${ }^{234} \mathrm{U}{ }^{238} \mathrm{U}$ and ${ }^{230} \mathrm{Th} \mathrm{F}^{234} \mathrm{U}$ activity ratio $(\mathrm{AR})$}

The uranium and thorium contents of a black shale can be affected by a number of syndepositional and postdepositional processes not readily manifested by elemental concentrations. An integrated isotopic approach, i.e. a study of the ${ }^{234} \mathrm{U} /{ }^{238} \mathrm{U}$ and ${ }^{230} \mathrm{Th} /{ }^{234} \mathrm{U}$ AR in each fraction of the radionuclides belonging to the same radioactive series, is necessary to yield information about the differential behaviour of these radionuclides in the environment. Under typical environmental conditions, the order of mobility has been reported as being $U>R a$ $>$ Th (Ivanovich et al, 1992).

The parent of both uranium decay series, ${ }^{238} \mathrm{U}$ and ${ }^{235} \mathrm{U}$, are chemically equivalent and their isotopic abundance ratio in all the leachates does not deviate from (133 \pm 9$)$, i.e. the typical ratio usually encountered in naturally occurring materials (Ivanovich et al, 1992). The experiment outlines the great discrepancy between the ${ }^{234} \mathrm{U} /{ }^{238} \mathrm{U}$ AR in the mineral and organic phases, as illustrated in Figure 3. It ranges from 0.8 (organic fraction) to 1.9 (carbonates). Interactions of mineral phases with fluids containing ${ }^{234} \mathrm{U}$ excess can contribute to $a^{234} \mathrm{U} /{ }^{238} \mathrm{U} A R>1$ in carbonate and apatite, provided that such interactions result in incorporation of uranium isotopes from fluids to carbonates/apatite by re-adsoption, co-precipitation on surfaces within pores of minerals. Potential fluid sources are ground water, metamorphic fluids, organic matter. The role of interactions of ground water with minerals can not be determined, since no data set is available on ${ }^{234} \mathrm{U} /{ }^{238} \mathrm{U}$ in ground water. Nevertheless, this mode of interactions is unlikely, since no radioactive disequilibrium is observed in ${ }^{238} \mathrm{U}$ decay series for the bulk sample. Another process leading to an activity ratio higher than unity is metamorphism. Previously published results indicate that uranium preferentially leached from granites to carbonates (Singh et al, 2003). According to this hypothesis, presence of measurable excess of ${ }^{234} \mathrm{U}$ would require the interaction process to occur on long time scale. One would also observe a deficit in ${ }^{234} \mathrm{U}$ in the siliceous fraction, whereas the experiment indicates that the corresponding ${ }^{234} U /{ }^{238} U A R$ is 
close to unity. Sequential extraction experiments tend to prove that uranium is sequestred, during early diagenesis, in organic-rich sediment by redox reactions and complexation with organic matter. The ${ }^{230} \mathrm{Th} /{ }^{234} \mathrm{U}$ AR in this organic fraction is higher than unity (1.2), indicating an overall enrichment of ${ }^{230} \mathrm{Th}$ over its parent ${ }^{234} \mathrm{U}$. This could be the result of a greater mobility of uranium, leading to a depleted content of this element relative to thorium. ${ }^{234} \mathrm{U}$ recoiling by alpha decay from the deposits is doubtless transferred into the carbonate/apatite fractions herewith producing $\mathrm{a}^{234} \mathrm{U} /{ }^{238} \mathrm{U}$ AR around 1.9 and 1.4, respectively. Additional support for this interpretation is the value of the ${ }^{230} \mathrm{Th} /{ }^{238} \mathrm{U}$ AR close to unity. ${ }^{230} \mathrm{Th}$ detected in the carbonate fraction (F3) and in the apatite one (F4) is produced by alpha decay of ${ }^{234} \mathrm{U}$. It is worth noting that there is a drastic disequilibrium between ${ }^{230} \mathrm{Th}$ and ${ }^{234} \mathrm{U}$ activity concentrations in both mineral fractions, as illustrated in Table 3 . This deficit in ${ }^{230} \mathrm{Th}$ is an additional proof of a continuous mobilization of uranium from another U-rich fraction to the carbonate/apatite one. The ${ }^{234} \mathrm{U} /{ }^{238} \mathrm{U}$ AR is very close to secular equilibrium in the resistant material (F6), whereas ${ }^{230} \mathrm{Th}$ activity is 4.5 higher than that of its grandparent ${ }^{238} \mathrm{U}$. Since organic matter and siliceous materials are closely associated, a possible transfer of actinides from silicates to organic components can be postulated. Owing to the low thorium mobility and the higher ability of humic acids to complex uranium than thorium, illustrated by our leaching experiments, the mobility of uranium is enhanced, leading to disequilibrium in the radioactive series. $A{ }^{234} U /{ }^{238} U A R$ near unity also implies that accessibility of crystals of quartz and clays to the interstitial water is limited. Therefore, the effect of alpha-decay related processes is mostly negligible.

\section{Conclusion}

A Timahdit's black shale specimen has been characterized in terms of ${ }^{234} \mathrm{U},{ }^{235} \mathrm{U},{ }^{238} \mathrm{U},{ }^{228} \mathrm{Th}$, ${ }^{230} \mathrm{Th},{ }^{232} \mathrm{Th}$ distributions, by measurements of some geochemically important elements (Al, Fe, $\mathrm{Si}, \mathrm{K}, \mathrm{Mn}, \mathrm{P}, \mathrm{Ca}$ ) and by XRD / SEM analysis. The main mineral phases, implied in the retention of trace elements, are quartz, clays, calcite and dolomite. Accessory minerals consist of pyrite, hydroxyl-apatite, anhydrite, feldspars. As in most other organic rich rocks, uranium is highly enriched in the shale. The actinide is associated predominantly with humic acids, the precursor of kerogen, in the +4 oxidation state. It has been deposited under anoxic reducing environment. 
Carbonates and apatite contribute also to the retention of uranium. The radionuclide that is the less mobile in this environment is thorium $\left({ }^{232} \mathrm{Th}\right)$, as was expected from its chemical properties, and in agreement with the most widely view in the literature. Sequential extraction procedure demonstrated that ${ }^{232}$ Th owns its source from continental landmass, it is partitioned between silicate minerals and pyrite.

The low activity ratios of ${ }^{232} \mathrm{Th} /{ }^{238} \mathrm{U}$ confers to the sediment a marine character. Moreover, the material presents a low porosity and there is no evidence of weathering, indicating that the systems remained closed over at least $10^{7}$ years. Considering the absence of stable or radioactive metals in interstitial water (only ultra-traces of such metals detected in the water leaching fraction of the sequential extraction procedure), the retention capacities of the black shale can be highlighted. Relevant metals are actually retained most probably via some active interfaces, resulting from an intimate association between organic matter and the inorganic matrix, especially silicates. The use of such black shale as a potential precursor of storage material for future possible high level waste repositories is under investigation.

\section{References}

Adams, J.A. \& Weaver, C.E. 1958. Thorium-uranium ratios as indicators of sedimentary processes: example of concept of geochemical facies. Bulletin American Association of Petroleum Geologists 42(2), 387-430.

Algeo, T.J., Maynard J.B., 2004, Trace-emlement behaviour and redox facies in core shales of Upper Pennsylvanian Kansas-type cyclothems. Chemical Geology, 206, 289-318.

Azouazi, M., Ouahidi, Y., Fakhi, S., Andres, Y., Abbe, J. Ch., Benmansour, M., 2001. Natural radioactivity in phosphates, phosphogypsum and natural waters in Morocco. Journal of Environmental Radioactivity 54, 231-242.

Bekri O., Ziyad M., 1991, Abstract presented at Oil Shale Symposium, Lexington, Kentucky, U.S.A. 
Benalioulhaj, N. 1991, Les formations à phosphates et à schistes bitumineux du bassin des oulad-Abdoun et du bassin de Timahdit (Maroc) : pétrographie, minéralogie, géochimie et environnement de dépôt, Thesis, Université Louis Pasteur, Strasbourg.

Blanco P., Vera Tome F., Lozano J.C., 2005, Fractionation of natural radionuclides in soils from a uranium mineralized area in the south-west of Spain, Journal of Environmental Radioactivity, 79, 315-330.

Delécaut, G., 2004, The geochemical behaviour of uranium in the Boom Clay, Thesis, Université catholique de Louvain, Louvain.

Galindo C., Mougin L., Nourreddine A.N., 2005, An improved radiochemical separation of uranium and thorium in environmental samples involving peroxide fusion, submitted to publication in Applied Radiations and Isotopes.

Ichcho S, 2003, Matériaux adsorbants à partir des schistes bitumineux de Timahdit et leurs applications dans l'élimination de métaux lourds et de bactéries, Thesis, Université Hassan II Mohammedia, Casablanca.

Ivanovich M., Harmon R.S., 1992, Uranium-series disequilibrium: applications to Earth, Marine, and Environmental Sciences, $2^{\text {nd }}$ edition, Clarendon Press, Oxford, New-York.

Klinkhammer G. P., Palmer M. R., 1991, Uranium in the oceans: Where it goes and why, Geochimica et Cosmochimica Acta, 55, 1799-1806.

Kochenov, A.V. Baturin, G.N., The paragenesis of organic matter, phosphorus and uranium in marine sediments, 2002, Lithology and Mineral Resources, 37, 107-120. 
Morvan K., Andres Y.,Mokili M.B., Abbe J.C., Fakhi S., 2001, Analyse du radium-226 en solution aqueuse par spectrométrie alpha, Ann. Chim. Sci. Mat, 26, S163.

Oumam M., Abourriche A., Hannache H., Bennamara A., Charrouf M., Pailler R., Naslain R., Bioactive properties of extracts from Moroccan oil shale 2002, J. Sci. Pharm. 70, 271-276.

Quevauviller Ph., Ure A., Muntau H., Griepink G., 1993, Improvement of analytical measurements with the BCR-programmme: single and sequential extraction procedures applied to soil and sediment analysis. International Journal of Environmental Analytical Chemistry 51, 231-235.

Rahhali, I. 1970, Foraminifères benthoniques et pélagiques du synclinal d'El Koubbat (MoyenAtlas, Maroc) Notes Serv. Géol. Maroc, 30, 225, 51-86.

Rosing MT, Frei R., 2004, U-rich Archaean sea-floor sediments from Greenland - indications of > 3700 Ma oxygenic photosynthesis, Earth and planetary Science Letters, 217, 237-244.

Ryan P.C, Wall A.J., Hillier S., Clark L, 2002, Insights into sequential chemical extraction procedures from quantitative XRD: a study of trace metal partiioning in sediments related to frog malformities, Chemical Geology, 184, 337-357.

Schultz M.K., Burnett ; W.C., Inn, K.G.W., 1998, Evaluation of a sequential extraction method for determining actinide fractionation in soils and sediments, Journal of Environmental Radioactivity, 40, 155-174.

Singh, S.K., Dalai, T. K., Krishnaswami S, 2003, $238 \mathrm{U}$ series isotopes and 232Th in carbonates and black shales from the Lesser Himalaya: implications to dissolved uranium abundances in Ganga-Indus ource waters, Journal of Environmental Radioactivity, 67, 69-90. 
Swanson V.E., 1956, Uranium in marine black shales of the United States. In LR Page H.E. Stocking and H.B. Smith Editors, Contributions to the geology of uranium and thorium by the United States Geological Survey and the Atomic Energy Commission for the United Nations International Conference on Peaceful Uses of Atomic Energy, Geneva, Switzerland, 1955, US Geol.Surv.Prof. Pap, 300, 451-456.

Taylor S.R.., Mc Lennan S.M., 1985, The continental crusts: its composition and evolution, Blackwell, Oxford.

Tessier A., Campbell P.G.C., Bisson M., 1979, Sequential extraction procedure for the speciation of particulate trace metals, Anal.Chem., 51, 844-851.

Wignall P.B., Meyers K.J., 1988, Interpreting the benthic oxygen levels in mudrocks: a new approach, Geology, 16, 452-455.

Wignall P.B., Newton, R, 1998, Pyrite framboid diameter as a measure of oxygen deficiency in ancient mudrocks, American Journal of Science, 298, 537-552.

Wilkin R.T., Barnes H.L., Brantley S.L., 1996, The size distribution of framboidal pyrite in modern sediments: an indicator of redox conditions. Geochimica Cosmochimica Acta, 60, 38973912.

Yudovich, Ya E., Ketris M.P., Merts A.V., 1990, Geochemistry and uranium ore genesis in black shale, Syktyvkar:Geonauka in Kochenov, A.V. Baturin, G.N., The paragenesis of organic matter, phosphorus and unanium in marine sediments, 2002, Lithology and Mineral Resources, $37,107-120$. 


\section{Acknowledgements}

This study was undertaken within the frame work of an International Cooperation network (PICS N801), sponsored by the CNRS (Institut National de Physique Nucléaire et de Physique des Particules, IN2P3) and the CNR of Morocco. 


\section{CAPTIONS OF FIGURES}

Figure 1:

a) Location of sampling point. b) lithography of the studied area.

Figure 2:

Radiochemical flow chart for uranium and thorium analysis by $\alpha$-spectrometry.

Figure 3:

Some mineral phases observed by SEM analysis.

Figure 4:

Leaching results for selected major elements, uranium and thorium.

\section{CAPTIONS OF TABLES}

Table 1:

Sequential extraction procedure ( $R T$ : room temperature).

Table 2:

Elementary analysis of the Timahdit's black shale (*: results from S. Ichcho (2003)).

Table 3:

Activity of several naturally occurring radionuclides in the Timahdit's black shale and in the fractions obtained by sequential extractions ( $D L$ : detection limit) 


\begin{tabular}{|c|c|c|c|}
\hline \multirow{2}{*}{ Fraction } & \multirow{2}{*}{ Extracting agent } & \multicolumn{2}{|c|}{ Extracting conditions } \\
\hline & & Shaking time & Temperature \\
\hline \multicolumn{4}{|l|}{ Method 1} \\
\hline F1. Water soluble & $30 \mathrm{~mL}$ deionised water & $2 \mathrm{~h}$ & $\mathrm{RT}$ \\
\hline F2. Exchangeable & $25 \mathrm{~mL} 1 \mathrm{M} \mathrm{MgCl}_{2}$ & $24 \mathrm{~h}$ & $\mathrm{RT}$ \\
\hline F3. Carbonates & $35 \mathrm{~mL} 1 \mathrm{M} \mathrm{CH} \mathrm{COONa}_{3}-1 \mathrm{M} \mathrm{CH}_{3} \mathrm{COOH} \mathrm{pH}=4.75$ & $24 \mathrm{~h}$ & RT \\
\hline $\begin{array}{l}\text { F4. Manganese / iron } \\
\text { hydroxides and oxides }\end{array}$ & $\begin{array}{l}35 \mathrm{~mL} 0.04 \mathrm{M} \mathrm{NH} \mathrm{NH}_{2} \mathrm{OH} \mathrm{HCl}-25 \% \mathrm{v} / \mathrm{v} \mathrm{CH} \mathrm{CH}_{3} \mathrm{COOH} \mathrm{pH}=2 \\
\text { (adjusted with } \mathrm{HNO}_{3} \text { ) }\end{array}$ & $24 \mathrm{~h}$ & $\mathrm{RT}$ \\
\hline \multirow{2}{*}{$\begin{array}{l}\text { F5. Organic matter }+ \\
\text { pyrite }\end{array}$} & $\begin{array}{l}25 \mathrm{~mL} 30 \% \mathrm{H}_{2} \mathrm{O}_{2}-15 \mathrm{~mL} 0.02 \mathrm{M} \mathrm{HNO}_{3}(\mathrm{pH}=2) \\
15 \mathrm{~mL} 30 \% \mathrm{H}_{2} \mathrm{O}_{2}-9 \mathrm{~mL} 0.02 \mathrm{MNO}_{3}(\mathrm{pH}=2)\end{array}$ & $\begin{array}{l}2 h \\
3 h\end{array}$ & $\begin{array}{l}85^{\circ} \mathrm{C} \\
85^{\circ} \mathrm{C}\end{array}$ \\
\hline & $35 \mathrm{~mL} 3.2 \mathrm{M} \mathrm{CH}_{3} \mathrm{COONa}$ in $20 \% \mathrm{HNO}_{3}$ & $0.5 \mathrm{~h}$ & $\mathrm{RT}$ \\
\hline F6. Residual & / & / & / \\
\hline \multicolumn{4}{|l|}{ Method 2} \\
\hline \multirow{2}{*}{ F1'. } & $15 \mathrm{~mL} 6 \mathrm{M} \mathrm{HCl}$ & $4 \mathrm{~h}$ & $\mathrm{RT}$ \\
\hline & $15 \mathrm{~mL} 48 \% \mathrm{HF}$ & $4 \mathrm{~h}$ & $\mathrm{RT}$ \\
\hline F2'. Residual & / & l & l \\
\hline
\end{tabular}

Table 1 


\begin{tabular}{|l|l|l|l|l|l|l|l|l|l|l|l|l|l|}
\hline Element & $\mathrm{C}$ & $\mathrm{K}$ & $\mathrm{Na}$ & $\mathrm{Ca}$ & $\mathrm{Mg}$ & $\mathrm{Al}$ & $\mathrm{Fe}$ & $\mathrm{P}$ & $\mathrm{Mn}$ & $\mathrm{Ti}$ & $\mathrm{Si}$ & $\mathrm{U}$ & $\mathrm{Th}$ \\
\hline $\begin{array}{l}\text { Concentration } \\
\left(\mathrm{mg} \cdot \mathrm{g}^{-1}\right)\end{array}$ & $216^{*}$ & 10.4 & $<4$ & 87.2 & 27 & 37.8 & 17.6 & 7.6 & 0.13 & 2.2 & 112 & 0.041 & 0.005 \\
\hline
\end{tabular}

Table 2 


\begin{tabular}{|c|c|c|c|c|c|c|c|c|}
\hline Fraction & ${ }^{238} U$ & ${ }^{235} \mathrm{U}$ & ${ }^{234} \mathrm{U}$ & ${ }^{232} \mathrm{Th}$ & ${ }^{230} \mathrm{Th}$ & ${ }^{228} \mathrm{Th}$ & ${ }^{234} \mathrm{U} /{ }^{238} \mathrm{U}$ & ${ }^{230} \mathrm{Th}^{/ 238} \mathrm{U}$ \\
\hline Bulk sample & $522 \pm 41$ & $26 \pm 2$ & $521 \pm 41$ & $21.9 \pm 2.1$ & $519 \pm 48$ & $19.5 \pm 2.0$ & $1.0 \pm 0.1$ & $1.0 \pm 0.1$ \\
\hline F1 & $4.0 \pm 0.4$ & $<$ LD & $7.4 \pm 0.6$ & $<\mathrm{DL}$ & $26 \pm 2$ & $<\mathrm{DL}$ & $1.8 \pm 0.2$ & $6.5 \pm 0.8$ \\
\hline F2 & $17 \pm 1$ & $1.1 \pm 0.2$ & $32 \pm 2$ & $<\mathrm{DL}$ & $2.9 \pm 0.9$ & $<\mathrm{DL}$ & $1.9 \pm 0.2$ & $0.17 \pm 0.05$ \\
\hline F3 & $53 \pm 3$ & $2.9 \pm 0.5$ & $100 \pm 5$ & $<\mathrm{DL}$ & $3.9 \pm 0.9$ & $<\mathrm{DL}$ & $1.9 \pm 0.1$ & $0.07 \pm 0.02$ \\
\hline F4 & $44 \pm 3$ & $2.1 \pm 0.4$ & $60 \pm 3$ & $<\mathrm{DL}$ & $4 \pm 2$ & $<\mathrm{DL}$ & $1.4 \pm 0.1$ & $0.09 \pm 0.05$ \\
\hline F5 & $394 \pm 22$ & $23 \pm 2$ & $308 \pm 18$ & $11.9 \pm 1.3$ & $371 \pm 66$ & $10.6 \pm 1.9$ & $0.78 \pm 0.06$ & $0.94 \pm 0.05$ \\
\hline F6 & $19 \pm 1$ & $0.8 \pm 0.2$ & $19 \pm 1$ & $11.4 \pm 1.3$ & $92 \pm 9$ & $10.0 \pm 1.8$ & $1.01 \pm 0.09$ & $5.4 \pm 0.7$ \\
\hline $\mathrm{HCl}+\mathrm{HF}$ leaching & $16 \pm 1$ & $0.8 \pm 0.1$ & $23 \pm 2$ & $13 \pm 1.4$ & $118 \pm 10$ & $9.5 \pm 1.1$ & $1.5 \pm 0.2$ & $7.4 \pm 0.8$ \\
\hline
\end{tabular}

Table 3 


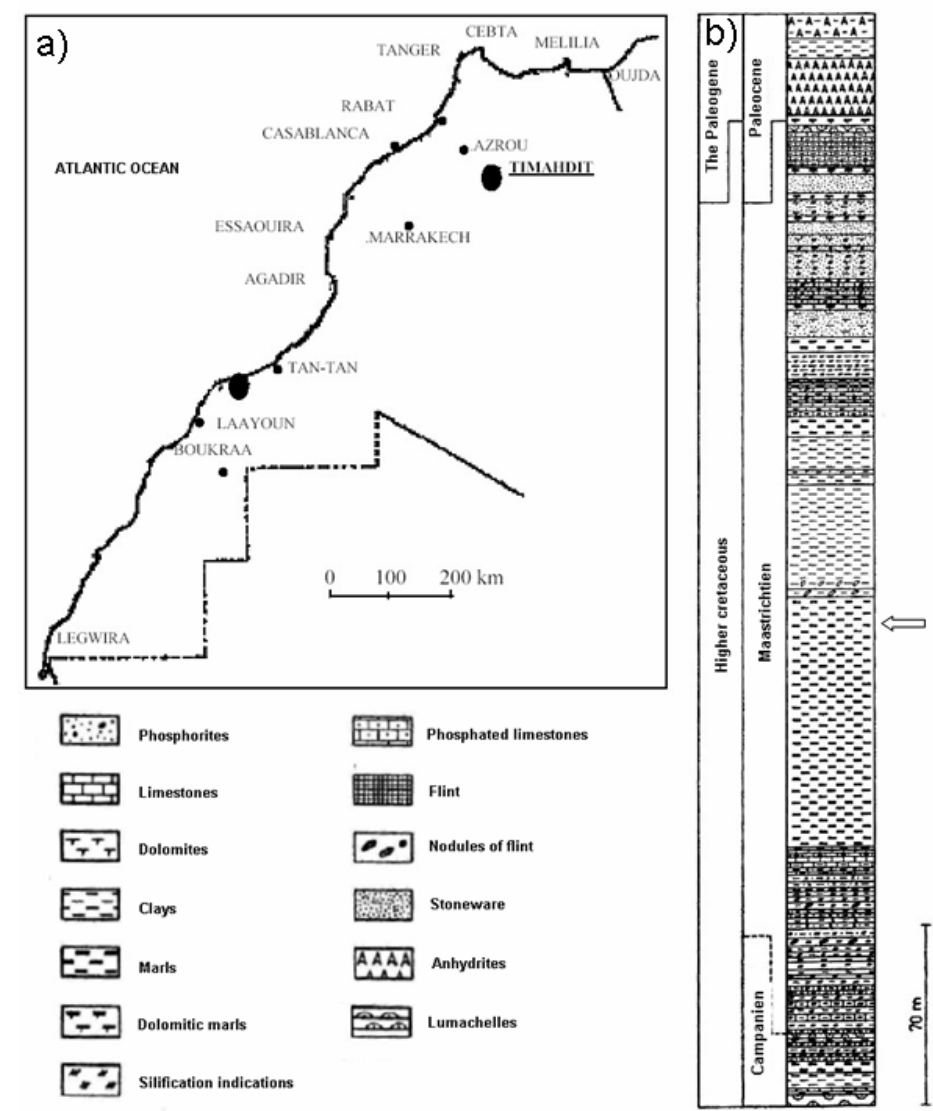

Figure 1 


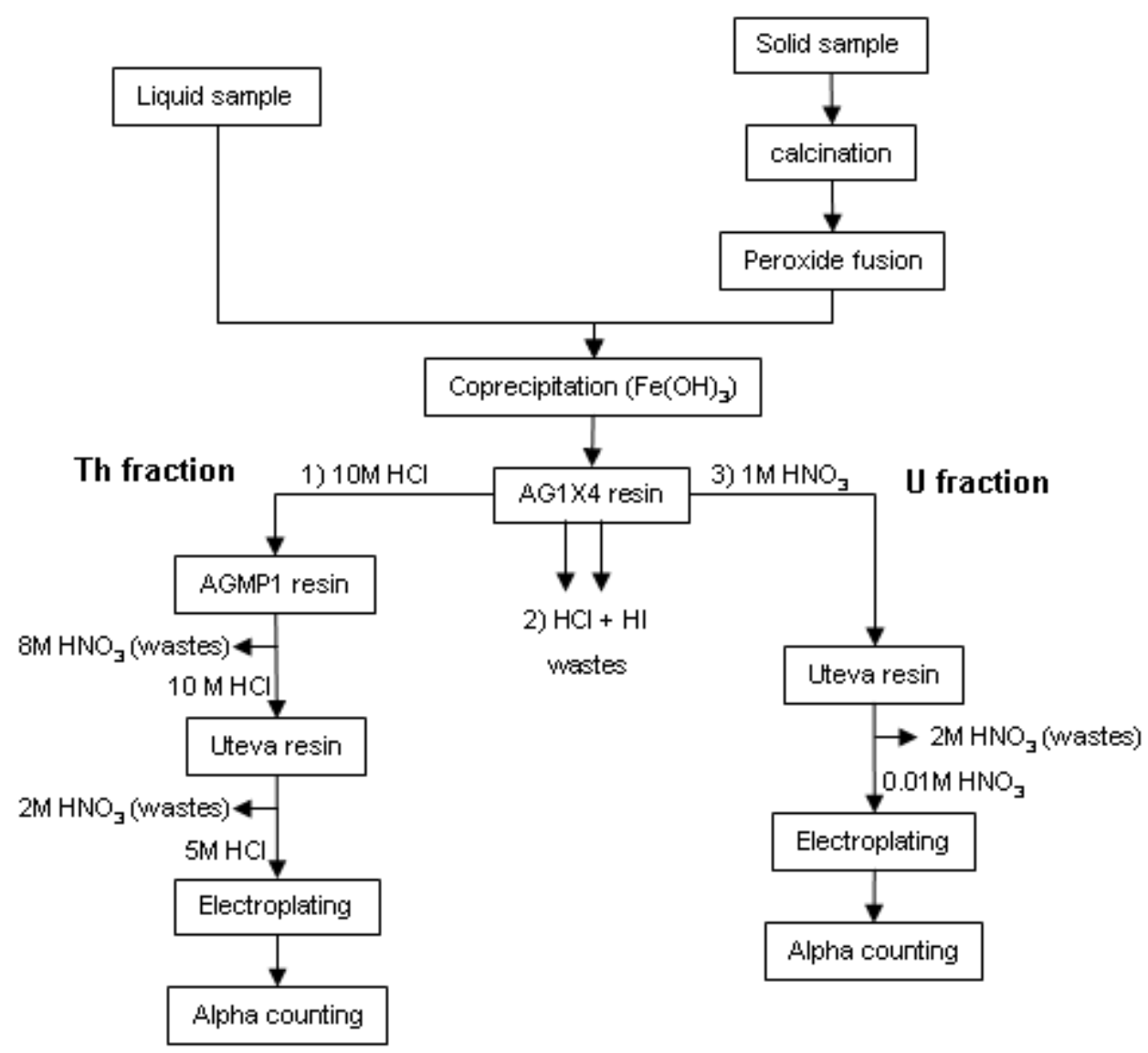

Figure 2 


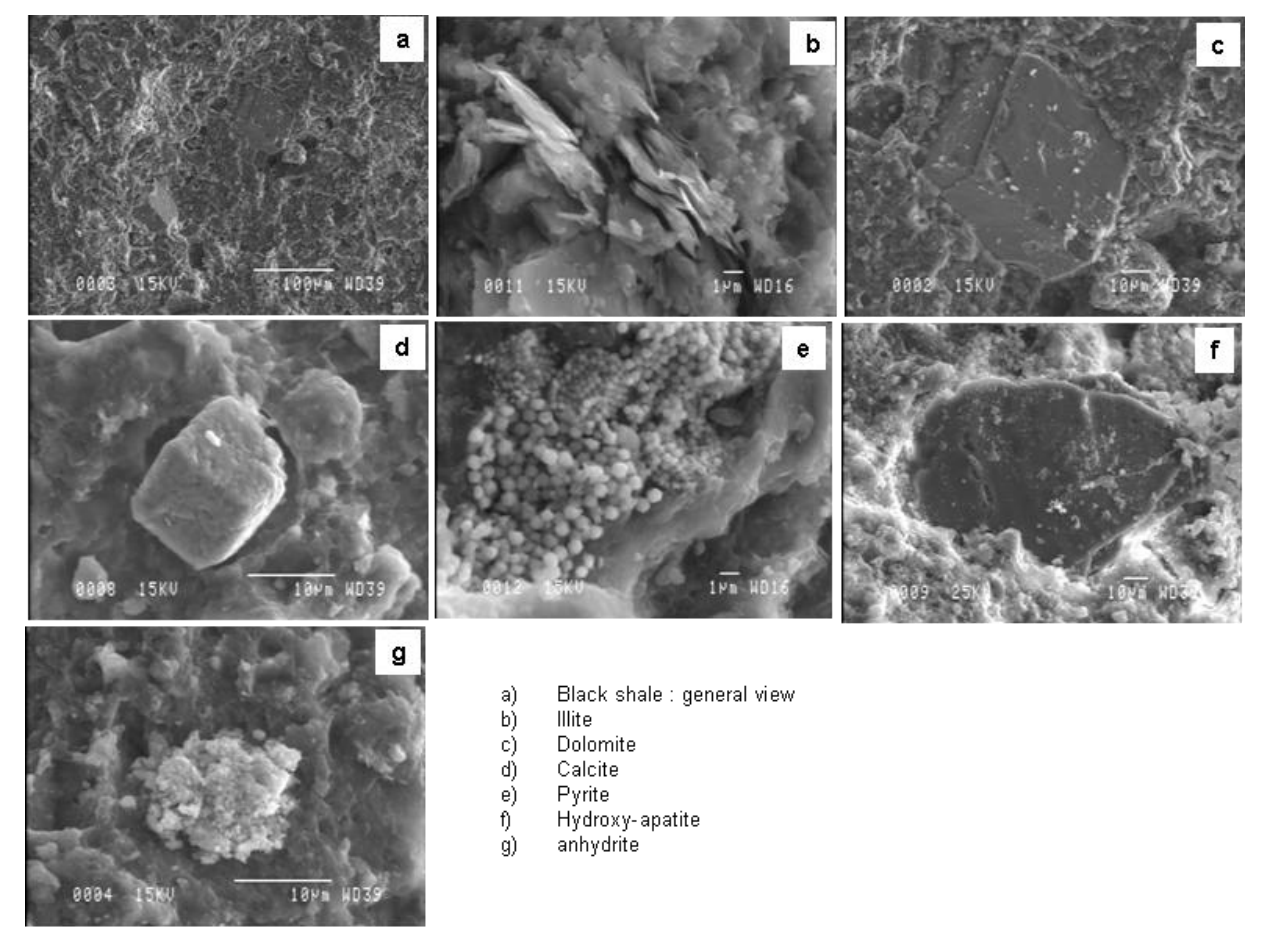

Figure 3 

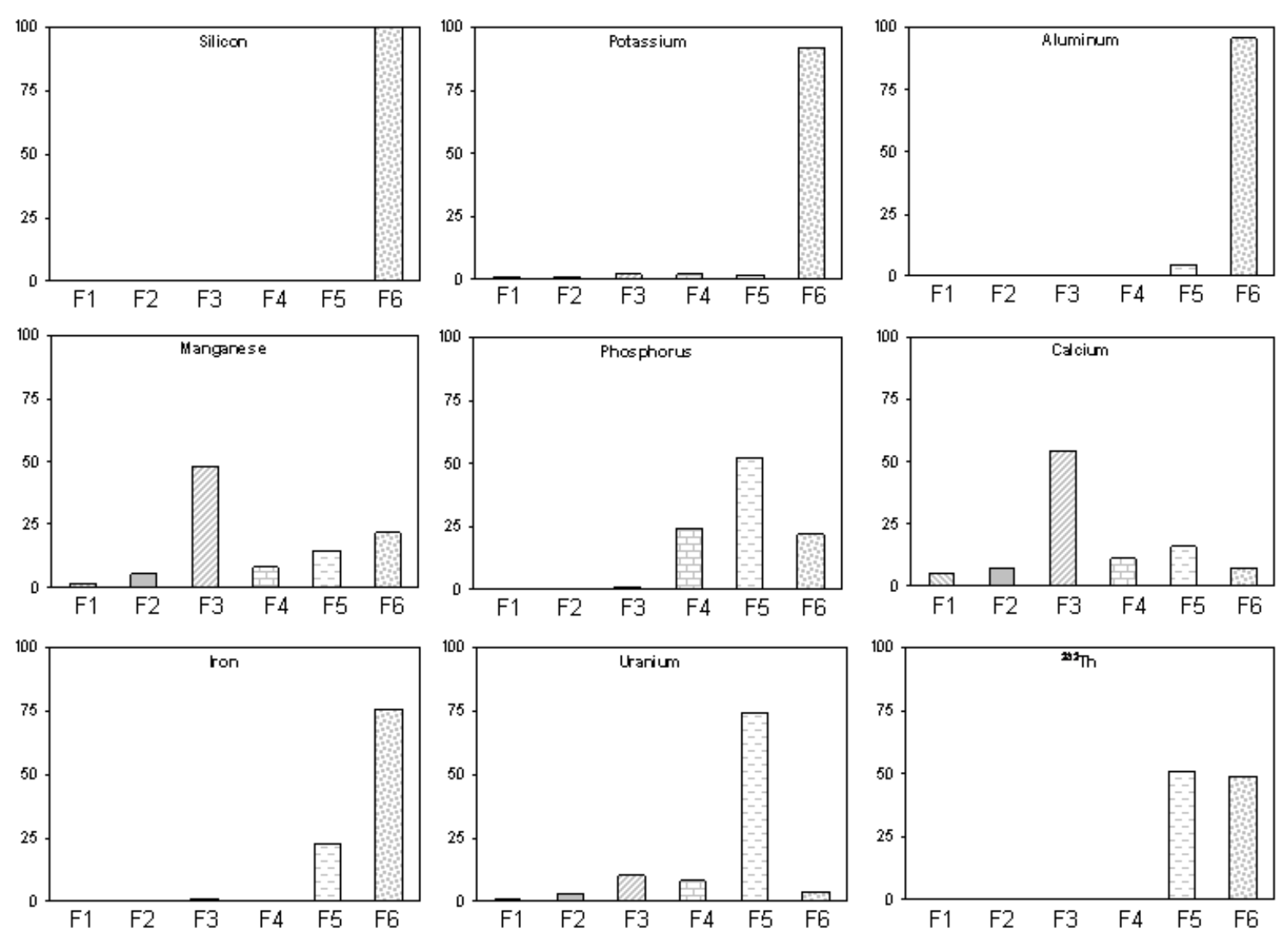

Figure 4 